It is doubtless true that if death does not occur from pulmonary embolism, clots may be removed by a process of lysis and the patency of the vessels may be restored. This case shows that this cannot be relied on to happen, and if severe secondary pulmonary hypertension is to be avoided with its attendant dyspnoea and disability, removal of embolus and clot may be necessary. Presumably whether a particular embolus may be dissolved by lysis or not will depend on its age. A recent soft embolus is more likely to be lysed than an older, rigid, and possibly partly organized one.

LORD BROCK, M.S., F.R.C.S., F.R.C.P.

Guy's Hospital and the Brompton Hospital, London.

H. NABIL, M.D.

Mehr Hospital, Teheran.

R. V. GIBSON, M.B., F.R.C.P.

Brompton Hospital, London S.W.3.

\section{Hypoglycaemic Coma Occurring during Treatment with Chlorpromazine and Orphenadrine}

\section{Brit. med. F., 1967, 4, 599-600}

Hypoglyeaemia may occur with several drugs in addition to those used in the treatment of diabetes. This report describes the findings in a patient presenting in hypoglvcaemic coma during treatment with chlorpromazine and orphenadrine. No such association appears to have been reported previously.

\section{Case Report}

A 53-year-old married woman was admitted to hospital in coma. For some years she had been under psychiatric care, and during the previnus two months had been treated with chlorpromazine 100 $\mathrm{mg}$. four times a day, together with trifluoperazine (Stelazine). One week before her admission the latter drug was replaced by orphenadrine (Disipal) $50 \mathrm{mg}$. three times a day. Three days later she began to have "attacks" of excessive sweating with dryness and paraesthesiae of the mouth and tongue. On the night of admission, though feeling normal on retiring to bed, she was found later to be groaning and unrousable. She was receiving no other drugs, was only a moderate smoker, and drank no alcohol.

On examination she was sweating profusely and was deeply comatose. Slow roving movements of the eyes were observed, but the pupils responded to light. There was no papilloedema or neck stiffness and Kernig's sign was negative. Both sides of the body moved slightly in response to painful stimuli ; the tone of the limbs was reduced, but the tendon reflexes were all present. The plantar resnonses were extensor. The pulse rate was 76 and regular; the blood pressure was $150 / 90$. Otherwise the examination showed nothing abnormal.

A clinical diagnosis of hypoglvcaemic coma was made by the house-officer on duty (J. G.). The patient was given $20 \mathrm{ml}$. of glucose $(25 \% \mathrm{w} / \mathrm{v})$ intravennusly, after which she quickly recovered consciousness. The blond sugar hefore treatment was $30 \mathrm{mg} . / 100$ $\mathrm{ml}$. (potassium ferricyanide method, normal fasting level 65-100 $\mathrm{mg} . / 100 \mathrm{ml}$ ), and after intravenous glucose was $57 \mathrm{mg} . / 100 \mathrm{ml}$.

Chlorpromazine and orphenadrine treatment was continued, and the following night she had another hypnglycaemic coma, during which the blood sugar fell to $44 \mathrm{mg} . / 100 \mathrm{ml}$. Recovery was rapid after $20 \mathrm{ml}$. of glucose $(50 \% \mathrm{w} / \mathrm{v})$ intravenously.

Investigations.-The peripheral hlood count, erythrocyte sedimention rate, urinalysis, and $x$-ray films of the chest and skull shnwed no abnormality. All tests of liver function were normal. The serum protein-bound iodine was $4.8 \mu \mathrm{g} . / 100 \mathrm{ml}$. The 24-hour urinary excretion of 17-ketosteroids was 103 (7.2) $\mathrm{mg}$., of 17-ketogenic steroids $3.2\left(\begin{array}{l}8 \\ 2\end{array}\right) \mathrm{mg}$., and of 17-hydroxvcorticosteroids 5.9 (11.2) mg. (The values in parentheses are repeat estimations while the patient was receiving orphenadrine alone.)

\section{Carbohydrate Homoeostasis}

Investigations were carried out during and after stopping treatment with the two drugs.

(a) During Treatment with ChInrpromazine and Orphenadrine.The fasting blood sugar was $55-65 \mathrm{mg} . / 100 \mathrm{ml}$., and the patient had a further episode of hypoglycaemic coma (see above) at this time. After tolbutamide (1 g. intravenously) the blood glucose (glucose oxidase method) fell from 65 to $29 \mathrm{mg}$. at 45 minutes, and slowly rose to 34 and $38 \mathrm{mg} . / 100 \mathrm{ml}$. at two and three hours respectively (Fig. 1). The fasting level of plasma insulin (measured by radioimmunoassay) was $9 \mu \mathrm{U} / \mathrm{ml}$. During the tolbutamide test the plasma levels of insulin were $14 \mu \mathrm{U}$ at $30 \mathrm{~min} ., 17 \mu \mathrm{U}$ at $45 \mathrm{~min} ., 11 \mu \mathrm{U}$ at $60 \mathrm{~min}$., and $12 \mu \mathrm{U}$ at $90 \mathrm{~min}$. (all levels being within normal limits). After oral glucose $(50 \mathrm{~g}$.) the blood glucose
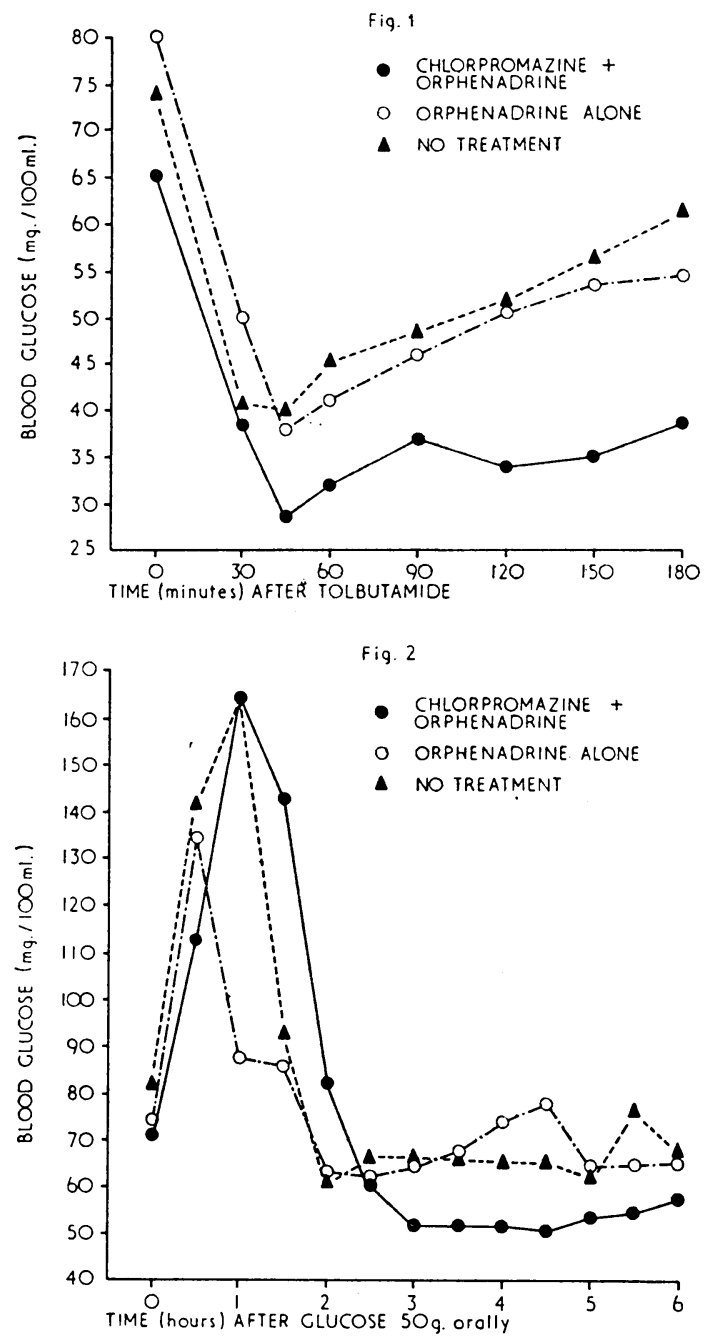

Fig. 1.-Effects of tolbutamide $(1 \mathrm{~g}$.) given intravenously on blond glucose levels. FIg. 2. - Six-hour glucose-tolerance tests. (Glucose estimared by the glucose oxidase methods in both instances.)

rose to $162 \mathrm{mg}$. at one hour, fell to $52 \mathrm{mg}$. at three hours, and remained below $60 \mathrm{mg} . / 100 \mathrm{ml}$. for the remainder of the six-hnur test (Fig. 2) The patient was starved for 72 hours, during which time the hlond glucose fell to $42-44 \mathrm{mg} . / 100 \mathrm{ml}$, hut no hrpoglvcaemic symptoms develnped. The response to glucagon $(1 \mathrm{mg}$. iniramuscularly) was normal. The blood glucose rose by $35 \mathrm{me} . /$ $100 \mathrm{ml}$. during the first 30 minutes, and thereafter slowly fell to a minimum value of $50 \mathrm{mg} . / 100 \mathrm{ml}$. at four hours. 
(b) During Treatment with Orphenadrine Alone.-One week atter stopping chlorpromazine the fasting blood sugar had risen to $77-88 \mathrm{mg} . / 100 \mathrm{ml}$. After tolbutamide the blood glucose fell to $38 \mathrm{mg} . / 100 \mathrm{ml}$. at 45 minutes, but reached two-thirds the fasting value at two and a half hours (Fig. 1). The six-hour glucosetolerance curve showed a normal pattern (Fig. 2).

(c) No Treatment.-Repeat studies one week later showed a normal fasting blood sugar, while the tolbutamide test (Fig. 1) and the six-hour glucose-tolerance test (Fig. 2) were both normal. It was therefore not felt justified to subject the patient to a further 72 hours of starvation.

No hypoglycaemic episodes or other abnormalities have emerged during surveillance for the past 18 months, and fasting blood sugars have been normal.

\section{COMMENT}

The patient's symptoms and two comas occurred in the postabsorptive state, responded quickly to glucose, and ceased when treatment was stopped.

Studies of chlorpromazine on carbohydrate metabolism have yielded conflicting results. Some reports have shown hyperglycaemia and decreased glucose tolerance (Courvoisier et al., 1953 ; Dobkin et al., 1954 ; Charatan and Bartlett, 1955), while other studies have found no effect on blood sugar and an increased tolerance (Donegani et al., 1959 ; Bonaccorsi et al., 1964).

Orphenadrine is a substituted derivative of diphenhydramine. None of this group of antihistamines has any known effect on carbohydrate metabolism, though some of the ethylene diamine group (such as antazoline) may cause asymptomatic reduction of blood sugar when given in high dosage (Goldner and Jauregui, 1954).

After tolbutamide the absolute fall in blood glucose was greater, and the rate of return towards normal was slower during treatment with both chlorpromazine and orphenadrine than with the latter alone, normality being achieved only when both were stopped. The normal circulating insulin levels, both fasting and during tolbutamide stimulation, suggest that the drugs did not stimulate its secretion; they also, along with the absence of further attacks of hypoglycaemia during the past 18 months, make it unlikely that the patient's symptoms were due to an insulinoma or to an undetected extrapancreatic tumour.

The therapy may have increased the effectiveness of action of normal quantities of secreted insulin. Another possibility is an increased tissue uptake of glucose due to a direct effect of the drugs, for orphenadrine inhibits aerobic metabolism (de Waart, 1958 ; Lewis and Van Petten, 1963).

There could have been an interference with humoral mechanisms normally maintaining the blood sugar. Chlorpromazine inhibits many of the peripheral actions of adrenaline, but is without effect on its hyperglycaemic action (Courvoisier et al., 1953). Impairment of the secretion of glucagon could contribute to hypoglycaemia, especially during fasting. But the normal response to glucagon in this patient excluded any significant impairment of glycogenolysis caused by interference with phosphorylase activity.

Growth hormone and A.C.T.H. play a part in maintaining the blood sugar, and both are under hypothalamic control (Reichlin, 1963). Chlorpromazine depresses the hypothalamus (Goodman and Gilman, 1965) and interferes with the release of several pituitary hormones (Christy et al., 1957) ; it could thereby interfere with carbohydrate homoeostasis. During the combined therapy the 24-hour excretion of 17-ketosteroids and 17-hydroxycorticosteroids was depressed, but after stopping chlorpromazine there was a rise in their excretion, suggesting an inhibitory effect of chlorpromazine on hypothalamic-pituitary mechanisms.

Investigation suggested that chlorpromazine had the greater hypoglycaemic effect. Yet carbohydrate homoeostasis became normal only when orphenadrine was also stopped, and the patient had been symptom-free initially on chlorpromazine alone. This, with their structural similarity, suggests a summative effect between the two drugs. Both share the grouping $-\mathrm{CH}_{2}-\mathrm{CH}_{2}-\mathrm{N}-$ with the ethylene diamines, but this alone is unlikely to be responsible. It is possible that summation of a direct peripheral effect of orphenadrine together with the central hypothalamic-pituitary effect of chlorpromazine may be sufficient to cause manifest hypoglycaemia.

Chlorpromazine and orphenadrine individually are commonly prescribed, but when used together the possibility of hypoglycaemia should be considered.

Our thanks are due to Dr. K. O. Black, under whose care this patient was admitted, for allowing us to publish details of the case. We also wish to thank Dr. K. W. Taylor for kindly performing the insulin radioimmunoassay determinations, and Dr. A. B. Anderson for the glucose oxidase determinations.

\section{RICHARD M. BUCKLE, M.A., M.D., M.R.C.P., Senior Registrar. \\ JoHN GuillebaUd, M.A., M.B., B.CHIR., House-physician.}

Department of Medicine, St. Bartholomew's Hospital, London E.C.1.

\section{REFERENCES}

Bonaccorsi, A., Garattini, S., and Jori, A. (1964). Brit. f. Pharmacol., 23, 93 .

Charatan, F. B. E., and Bartlett, N. G. (1955). 7. ment. Sci., 101, 351.

Christy, N. P., Longson, D., Horwitz; W. A., and Knight, M. M. (1957). f. clin. Invest., 36, 543.

Courvoisier, S., Fournel, J., Ducrot, R., Kolsky, M., and Koetschet, P. (1953). Arch. int. Pharmacodyn., 92, 305.

Dobkin, A. B., Gilbert, R. G. B., and Lamoureux, L. (1954). Anaesthesia, 9, 157.

Donegani, G., Scarzella, R., and Zanalda, A. (1959). Arch. Sci. méd., 108, 531.

Goldner, M. G., and Jauregui, R. H. (1954). Amer. F. dig. Dis., 21, 160. Goodman, L. S., and Gilman, A. (1965). The Pharmacological Basis of Therapeuttcs, p. 167 New York.

Lewis, J. J., and Van Petten. G. R. (1963). Brit. F. Pharmacol., 20, 462. Reichlin, S. (1963). New Engl. 7. Med., 269, 1182, 1246, 1296. de Waart, C. (1958). Acta physiol. pharmacol. neerl., 7, 403. 